\title{
The Burden of Genetic and Epigenetic Traits in Prematurity
}

Reproductive Sciences

2018, Vol. 25(4) 47I-479

(C) The Author(s) 2017

Reprints and permission:

sagepub.com/journalsPermissions.nav DOI: $10.1|77 / 19337| 9 \mid 177 / 8270$

journals.sagepub.com/home/rsx

(S)AGE

\author{
Bruna Ribeiro de Andrade Ramos, PhD' \\ and Márcia Guimarães da Silva, PhD'
}

\begin{abstract}
Despite decades of investigations and accumulated scientific knowledge, preterm birth (PTB) remains a significant burden worldwide. Several mechanisms have been proposed to explain this condition, and a number of risk factors from infectious to behavioral and genetic/epigenetic factors influence this outcome. The heritability of PTB is estimated to be $17 \%$ to $36 \%$, which demonstrates that genetic predisposition plays a key role in PTB. Structural DNA modifications without changes in the DNA sequence and post-transcriptional regulation also have an impact on gene expression and thus influence pregnancy outcomes. There is a complex interplay between environmental factors and the individual's genetics and epigenetics that may culminate in PTB, but the complete regulatory pathways and networks involved in this context are still unclear. Here, we outline what is known so far about the genetic and epigenetic factors involved in preterm delivery, including polymorphisms, DNA methylation, and microRNAs, and suggest fields for research.
\end{abstract}

\section{Keywords}

preterm birth, prematurity, genetics, polymorphisms, epigenetics, microRNA, DNA methylation

Preterm birth (PTB) is a worldwide health concern that accounts for up to $70 \%$ of perinatal morbidity and mortality, ${ }^{1}$ totalizing 4 million neonatal deaths annually ${ }^{2}$ and costing over 26 billion in the United States alone. ${ }^{3}$ Despite decades of investigations and accumulated scientific knowledge in this area, we have not yet been able to significantly reduce the prevalence of prematurity, and both developed and developing countries face stable, although not equally distributed rates of PTB. ${ }^{4}$ Preterm infants are often prone to infections and are at risk of cerebral palsy, enterocolitis, chronic lung disease, and cognitive delay among other morbidities that may be a burden to be carried throughout the newborn's life. ${ }^{5}$

Preterm birth can be divided into 2 major clinical groups: medically indicated PTB due to maternal and/or fetal compromise, such as hypertensive disorders, placental abruption, chronic diabetes, cardiac disease, fetal malformation, and fetal growth restriction, and spontaneous $\mathrm{PTB}$, hereafter referred to simply as PTB, triggered by preterm labor (PTL) and/or preterm premature rupture of membranes (PPROM). This latter category is a multifactorial and complex condition for which several mechanisms have been proposed. ${ }^{6}$ Bacterial vaginosis and intrauterine infections, for example, are known risk factors for PTB. ${ }^{7}$ These factors can lead to an inflammatory state at the maternal-fetal interface that deviates from the physiological balance required for the maintenance of pregnancy. ${ }^{6}$ Bacterial or viral antigens are recognized by toll-like receptors (TLR) on the surface of leukocytes and chorioamniotic membranes, leading to the activation of nuclear factor (NF)- $\kappa \mathrm{B}$. Nuclear factor- $\kappa \mathrm{B}$ enters the nucleus and activates the transcription of proinflammatory cytokines such as interleukin (IL)-1, IL-6, and tumor necrosis factor (TNF). ${ }^{8}$ Increased levels of these cytokines induce the production of prostaglandin and metalloproteinases that, in turn, lead to cervical ripening, membrane rupture, and myometrial contractility, culminating in PTB. ${ }^{6,9}$

Although infectious events are present in approximately $30 \%$ of cases with PTB, the etiology of the other $70 \%$ of cases remains to be identified. ${ }^{10,11} \mathrm{~A}$ second risk factor of great impact on gestational outcomes is maternal smoking status. Smoking habits have been associated with prematurity, ${ }^{12,13}$ and the risk of PTB attributable to cigarette exposure has been estimated to be $25 \%{ }^{14}$ It has already been demonstrated by extensive research that components of cigarette extract induce oxidative stress and the senescence of fetal membranes via the activation of p38MAPK, leading to the activation of PTB pathways. ${ }^{15}$

\footnotetext{
' Department of Pathology, Botucatu Medical School, São Paulo State University—UNESP, São Paulo, Brazil

\section{Corresponding Author:}

Bruna Ribeiro de Andrade Ramos, Department of Pathology, Botucatu Medical School, São Paulo State University—UNESP, Distrito de Rubião Júnior, I8618686, Botucatu, São Paulo, Brazil.

Email: bru_rar@hotmail.com
} 
Although common causes of PTB, infections and smoking status are unable to completely explain the high rates of prematurity worldwide. Other reported risk factors for PTB include advanced maternal age (over 40), extreme body mass index $\left(<18.5\right.$ or $\left.>35 \mathrm{~kg} / \mathrm{m}^{2}\right)$ and, importantly, genetic predisposition. ${ }^{16}$ It is very likely that genetic predisposition may help explain most of the remaining cases and even contribute to those in which other risk factors are present. It has been demonstrated that genetic factors play a key role in PTB. Mothers with previous or family history of PTL or PPROM are at risk of the reoccurrence of these complications. ${ }^{17,18}$ Twin studies estimate the heritability of PTB as $17 \%$ to $36 \%{ }^{19,20}$ Other evidence linking genetic predisposition, epigenetic/environmental contributions, and PTB includes the striking difference among PTB rates in different ethnic groups. ${ }^{21,22}$ Furthermore, a large meta-analysis has recently emphasized the impact of genetic and epigenetic traits in gestational outcomes as prior PTB was found to be the strongest individual risk factor for this complication in a data set comprising 4.1 million births. ${ }^{16}$

Unlike Mendelian diseases caused by highly penetrant gene mutations in a single gene, PTB is rather influenced by several concurrent mutations in different genes and by gene-environment interactions. Large-scale gene expression profiling and genome-wide studies have identified altered expression and genetic polymorphisms in several proinflammatory, angiogenic, and tissue turnover-related genes in placentas from pregnancies complicated by PTL when compared to normal term deliveries. ${ }^{11,23,24}$ Most of these studies have reported an influence of the fetal genome in the predisposition to PTB although to a lesser extent than the influence of maternal genetic factors. ${ }^{25,26}$ Moreover, several studies have shown that modifications not only in the DNA sequence but also in its structure, that is, epigenetic changes, can affect the gestational outcome. ${ }^{27,28}$

It seems clear that there is a complex interplay between environmental factors (ie, infections and others) and the individual's genetic and epigenetic settings that may culminate in PTB, but the complete regulatory pathways and networks involved in this context are still unclear. Here, we outline what is known so far about the genetic and epigenetic involvement in preterm delivery in terms of polymorphisms, microRNAs (miRNA), and DNA methylation and suggest fields for research.

\section{Single-Nucleotide Polymorphisms and PTB}

\section{Polymorphisms in Proinflammatory Genes}

As inflammation has been postulated to be the major mechanism causing PTL and PPROM, and consequently PTB, one could expect molecules involved in the regulation of the innate immune response to be chosen as targets of genetic studies in PTB. Another gene set that has been largely evaluated in such studies are those involved in the synthesis and degradation of the extracellular matrix considering their role in the integrity of chorioamniotic membranes. Single-nucleotide polymorphisms
(SNPs) in these genes often affect protein expression and may modulate PTB. As the main source of genetic variability in human genome, SNPs have been extensively studied in pregnancy complications.

\section{Cytokines}

Interleukin 1 beta (IL-1 $)$ is the prototypic proinflammatory cytokine and has been consistently associated with PTL. High intra-amniotic levels of IL-1 $\beta$ induce the synthesis of prostaglandin E2 by cyclooxygenase 2 and consequently lead to myometrial contractility and labor. Studies have reported associations between PTB and specific SNPs in this gene, such as the maternal ILIB-511 TT genotype. ${ }^{29}$ Similarly, the $I L 1 B+3953 \mathrm{C}>\mathrm{T}$ polymorphism was associated with a reduced risk of PTB in Austrian Caucasian women in a study by Schmid et al. ${ }^{30}$ The SNPs in the gene that encodes for IL- $1 \alpha$, a cytokine from the same family as IL-1 $\beta$, were screened by Yilmaz et $\mathrm{al}^{29}$ and the fetal $I L 1 A-4845$ TT genotype was shown to be an independent risk factor for PTB in a Turkish population. Interleukin 1 beta and IL-1 $\alpha$ bind to IL-1 receptor to trigger the inflammatory cascade. A polymorphism located in the gene that encodes for the IL-1 receptor antagonist, an inhibitor of IL-1 $\beta$ activity, was reported to increase the odds of PTB when both mother and child carried the $I L-1 R N$ allele 2 among nonHispanic white women in Michigan (United States) in a large cohort of 1371 pregnant women. ${ }^{31}$

Genetic alterations were also investigated within $T N F A$, which encodes for TNF- $\alpha$, an important modulator of pregnancy. The variation in the promoter region at position -308 is by far the most studied SNP. Although some authors have not observed any association between this SNP and PTB, ${ }^{29,32}$ the majority of studies link the TNFA-308 A allele to PTB. ${ }^{33-35}$ Our group has recently reported a protective role against PPROM and PTL for the low-producing TNF-238 A allele and TNFA$308 G$-238 $A$ haplotype in samples from Brazilian women. ${ }^{12}$ Findings by Liang et $\mathrm{al}^{35}$ suggest that one TNFA-308 $G$ allele and therefore the monoallelic full expression of TNF- $\alpha$ is protective against PTB. Several studies evaluated polymorphisms in the TNF receptor, and it was observed that the risk of PTB was higher among African American women when both mother and child carried the TNFR 2 allele. ${ }^{31}$

Another target for SNP studies in this field is the cytokine considered to be the main predictor of PTL, IL-6, a cytokine also associated with PPROM. ${ }^{36,37}$ The -174 polymorphism in the promoter region alters protein expression and has been linked to PTL in Polish women in the presence of the in tandem polymorphism $I L 1 R N * 2 .{ }^{38}$ Velez et $\mathrm{al}^{39}$ correlated variations in IL6 and IL6R genes with IL- 6 concentration in amniotic fluid in Caucasian fetal samples and African American maternal samples of patients with PTB. Various other cytokines regulate birth timing. Speer et $\mathrm{al}^{40}$ correlated the mutant fetal allele for interferon $\gamma($ IFN- $\gamma$ ), which produces high levels of the protein, to the PTB phenotype, conditioned on maternal genotype from American population, thus demonstrating the importance of maternal-fetal and environmental interactions. It is rather 
likely that a combination of different polymorphisms in a number of proinflammatory genes predispose to adverse gestational outcomes. Haplotype analysis in Brazilian population demonstrated association between the TNFA GG/IL-6 GG/IFNG AA and susceptibility to PTB. ${ }^{33}$

\section{Toll-Like Receptors}

A specific set of bacterial epitopes, the pathogen-associated molecular patterns (PAMPS), are recognized by TLR, a class of pattern recognition receptors (PRRs). Human trophoblast cells express TLR 1, 2, 3, 4, 5, 6, 9 and 10, which seem to be regulated in a temporal manner throughout pregnancy. ${ }^{41-43}$ As mentioned before, binding of PAMPS to TLR dimers initiates the production of inflammatory mediators via NF- $\mathrm{KB}$, leading to the inflammatory events that culminate in PTB.

In a study performed with Brazilian women who underwent PTL and PPROM, our group described the association between a polymorphism in TLR2 (rs4696480) and increased risk of PPROM. ${ }^{12}$ Such allele was previously associated with risk of sepsis by gram-positive bacteria. ${ }^{44}$ In a Polish population, Bitner et $\mathrm{al}^{45}$ studied polymorphisms in TLR4 that lead to lower production of IL- $1 \alpha$ after lipopolysaccharide (LPS) stimulation. ${ }^{46}$ The authors observed that maternal carriage of the hyporesponsive TLR4-1196 T allele, but not for another hyporesponsive allele $T L R 4-896 \mathrm{G}$, was associated with reduced risk of PTB before the 33rd week of gestation. ${ }^{45}$

\section{Other Genes}

A whole set of polymorphisms in other genes involved in several system pathways have also been linked to PTB. Polymorphisms in genes related to the endocrine system can lead to structural changes in the uterus and the cervix that are hormone-mediated. A functional decrease in progesterone levels is a mechanism of loss of uterine quiescence, and SNPs in the progesterone receptor have been associated with PTB by some studies such as the $\mathrm{G}$ allele in rs $471767,{ }^{47,48}$ although some authors did not observe this association. ${ }^{49}$ Regarding oxytocin, an inducer of myometrial contractility, a research group in Austria $^{50}$ observed that a specific haplotype combination (rs2254298 A allele, rs2228485 C allele, and rs237911 G allele) was significantly associated with increased risk of PTB, but when analyzed separately, none of these SNPs were associated with this complication. By linkage analysis, Haataja et $\mathrm{al}^{51}$ identified the gene that encodes for insulin-like growth factor receptor 1 as a potential PTB-predisposing gene among families of Finnish origin. The same group found that a CAG repeat polymorphism located within exon 1 of the $A R$ gene in the offspring is associated with PTB. ${ }^{52}$ Polymorphisms in genes that regulate other body systems such as tissue remodeling, angiogenesis, and metabolism have also been studied in patients with PTB but represent a less common source of risk of this pathology. ${ }^{53}$ These studies show that genes involved in multiple pathways determine the heterogeneity of PTB and may also contribute to PTB susceptibility.

\section{Maternal Inheritance}

Contributing to the notion that genetic inheritance underlies adverse gestational outcomes, it has been hypothesized that polymorphisms in mitochondrial DNA could increase the risk of PTL and PPROM. Although epidemiological studies have indicated that the recurrence of PTB is maternally associated, suggesting that mitochondrial variants may contribute to the risk of PTB, the investigation of mitochondrial SNPs by genome-wide association study (GWAS) showed no association with PTL or PPROM after a meta-analysis in a study on Danish and Norwegian populations. ${ }^{54}$ The authors discuss other mechanisms of maternal inheritance not yet investigated such as gene imprinting. Nonetheless, an evaluation regarding mitochondrial polymorphisms and PTB merits further investigations.

Despite all these efforts, scientists are yet to find a "genetic preterm signature" able to confidently predict the gestational outcome, as many of these studies have provided heterogeneous results concerning the effect of specific polymorphisms in PTB. This is partially explained by the variety of methods used in these studies and by the differences in the populations evaluated, especially because most studies do not perform a biological evaluation of genetic background and only take into consideration self-reported ethnicity, which has very limited reliability for most populations. ${ }^{55}$ Moreover, the heterogeneity of PTL may cloud significant findings. Additionally, combined maternal and fetal haplotypes and their interactions are rarely taken into consideration. The application of homogeneous methods and accurate ethnic discrimination may provide more reliable information in the near future when genetic studies should be specifically validated for each population. What seems to be relatively consistent so far as for the role of SNPs in the development of PTB is the presence of certain alleles repeatedly described in women with PTB across the globe, such as the alleles $I L 6-174 \mathrm{G}$ and TNFA $-308 \mathrm{~A} \cdot .^{33-35,38} \mathrm{~A}$ summary of the studies cited here is listed in Table 1.

\section{The Role of Epigenetics in PTB}

Epigenetics refers to modifications to the DNA structure without changes in the DNA sequence, which produce heritable and stable, but potentially reversible, alterations in the transcriptional potential of a cell. A number of recent studies have supported the hypothesis that epigenetic alterations induced by pregnancyrelated risk factors may influence the risk of PTB.

\section{DNA Methylation and Chromatin Remodeling}

The addition of methyl groups at position 50 of the cytosine pyrimidine ring in $\mathrm{CpG}$ dinucleotides converts cytosine to 5methylcytosine. Highly methylated areas of the genome, especially in promoter regions, can disrupt transcription factor binding and therefore are less transcriptionally active. These changes lead to chromatin remodeling and transcriptional silencing. 
Table I. Summary of Studies on Polymorphisms Cited.

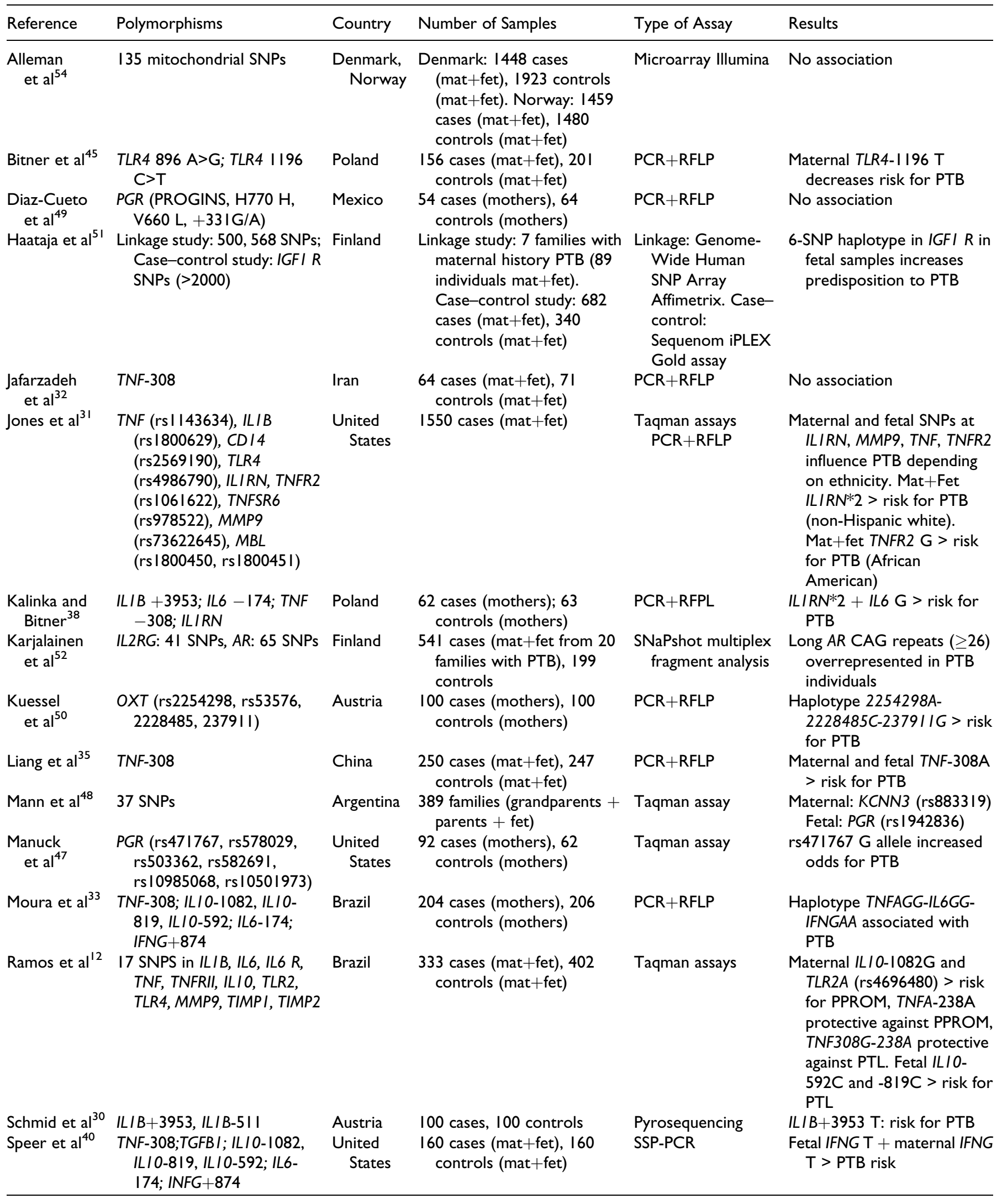


Table I. (continued)

\begin{tabular}{|c|c|c|c|c|c|}
\hline Reference & Polymorphisms & Country & Number of Samples & Type of Assay & Results \\
\hline Yilmaz et $\mathrm{al}^{29}$ & $\begin{array}{l}\text { ILIA (rs4845); ILIB-5II; } \\
\text { TNF-238, TNF-308 }\end{array}$ & Turkey & $\begin{array}{l}200 \text { cases }(\mathrm{mat}+\mathrm{fet}), 202 \\
\text { controls (mat }+\mathrm{fet})\end{array}$ & $\mathrm{PCR}+\mathrm{RFLP}$ & $\begin{array}{l}\text { Maternal: TNF-238G and } \\
\text { ILIB-5 I IG > PTB risk. } \\
\text { Fetal: TNF-238GA, ILIA } \\
\text { 4845G, IL I B-5 I IG > PTB } \\
\text { risk }\end{array}$ \\
\hline
\end{tabular}

Abbreviations: AR, Androgen receptor; IFNG, interferon gamma; ILIA, interleukin I alpha; ILIB, interleukin I beta; ILIRN, interleukin I receptor antagonist; IL2RG, interleukin-2 receptor gamma subunit; IL6, interleukin 6; IGFI R, insulin-like growth factor receptor I; KCNN3, small conductance calcium activated potassium channel isoform 3; mat+fet, maternal and fetal samples; MBL, mannan-binding lectin, MMP9, metalloproteinase 9; OXT, oxytocin; OXTR, oxytocin receptor; PCR+RFLP, Polymerase chain reaction followed by restriction fragment length polymorphism; PGR, progesterone receptor; PTB, preterm birth; PTL, preterm labor; PPROM, preterm premature rupture of membranes; SSP-PCR, single specific primer polymerase chain reaction; TGFB, transforming growth factor beta I; TLR4, Toll-like receptor 4; TNFRSF6, Fas; TNF, tumor necrosis factor; TNFRII, tumor necrosis factor receptor 2.

Changes in DNA methylation patterns have already been described in adverse pregnancy outcomes. Wang et $\mathrm{al}^{27}$ demonstrated that epigenetic regulation by DNA methylation at $M M P 1$ promoter correlates with its expression in the amnion and with the susceptibility to PPROM. Lower methylation in the $M I C B$ gene in peripheral leukocytes was reported in African American women who underwent PTB in comparison to women who delivered at term. MICB is a constituent of major histocompatibility complex class I involved in the initiation of immune responses; the reduced methylation observed in patients with PTB leads to increased expression of this gene. ${ }^{56}$ $\mathrm{Kim}$ et $\mathrm{al}^{28}$ investigated genome-wide methylation signatures that could distinguish between term and preterm patients using amniotic tissues from women in Argentina and in the United States. They identified that gene sets involved in the modulation of cellular behavior and tissue maintenance and organization are differently methylated between PTB and term delivery groups, which is in line with the importance of intact fetal membranes in the maintenance of pregnancy. Differential methylation patterns were also reported in fetal samples. Preterm and term neonates were shown to present distinct DNA methylation patterns in leukocytes from umbilical cord blood. ${ }^{57}$

Environmental factors are strongly associated with epigenetic modulation. For instance, the epigenome can be modified by diet. Folate and vitamin $\mathrm{B}_{12}$ are methyl donors, and the deficiency of these micronutrients correlates with altered DNA methylation. ${ }^{58,59}$ Moreover, low folate intake during pregnancy is a well-known risk factor for neural tube defects, and observational studies have indicated that adequate levels of this nutrient are associated with higher birth weight and fewer preterm births. ${ }^{60,61}$ In that way, it seems plausible that an inappropriate diet could facilitate PTB by still not completely known epigenetic mechanisms.

Two large studies have shown that environmental exposure has a strong impact on birth timing. Porter et $\mathrm{al}^{62}$ studied women in Alabama and concluded that those living within 5 $\mathrm{km}$ of high-polluting plants had a 5-fold higher risk of presenting with PTB when compared to those outside these areas, even after adjustments for age, socioeconomic status, and ethnicity. Similarly, Ferguson et $\mathrm{al}^{63}$ demonstrated that American women with high blood levels of phthalate metabolites (substances found in food and cosmetics) had increased odds of PTB regardless of other risk factors. While there is still much to learn regarding the mechanisms by which environmental exposures alter epigenetics and thus predispose to adverse gestational outcome, studies in this area hold the promise of having a direct positive impact on PTB rates, since epigenetic risks are modifiable risks.

Importantly, these changes in methylation may result in long-term consequences. In experimental models, it was shown that toxins such as bisphenol A (BPA) alter DNA methylation in the mouse uterus and that these alterations, while reversible upon dietary intervention, may persist for 2 subsequent generations. ${ }^{64}$ Burris et al ${ }^{65}$ found that improving the perinatal environment is critical, as it affects not only the exposed fetus but also subsequent generations. Moreover, it is worth noting that the epigenetic changes that occur in the fetus during development are partially responsible for the early onset of adult diseases observed in preterm neonates. ${ }^{66}$

DNA methylation is heritable to a certain degree. By comparing methylation status across the genome from mothers and unrelated fetuses, Parets et al ${ }^{56}$ identified over $5000 \mathrm{CpG}$ sites in which maternal and fetal methylation were associated. The authors reported that these sites were more likely to be located in genes that modulate cardiovascular, metabolic, and immune pathways, which is in agreement with the hypothesis of the developmental origin of health and disease which states that the perinatal environment affects adult health. Moreover, most of these CpG sites overlapped SNPs, which partly explains the hereditability of methylation and indicates the accumulated influence of polymorphisms in gestational outcome and the intricate relationship between epigenetic mechanisms and gene expression.

While a long-term epigenetic signature has been suggested for PTB,${ }^{56}$ until present, it is not clear whether differential 
methylation is a reflection of developmental differences or to what extent they may lead to long-term consequences, a question that can only be elucidated by future longitudinal studies.

\section{MicroRNAs}

MicroRNAs are small (20-22 nucleotides) non-coding RNAs that modulate gene expression in many physiological settings by destabilizing or inhibiting the translation of target messenger RNA (mRNAs) at the posttranscriptional level. ${ }^{67}$ The miRNAs form the RNA-induced silencing complex (RISC) that binds to the $3^{\prime}$ untranslated region ( $3^{\prime}$-UTR) of specific target genes to regulate their expression. Alternatively, it has been recently shown that the RISC complex may bind to the $5^{\prime}$-UTR, possibly acting to stabilize the target mRNA ${ }^{68} \mathrm{~A}$ large number of miRNAs have been identified and/or predicted, and in humans it is estimated that $30 \%$ to $50 \%$ of genes are potential targets for miRNA regulation. ${ }^{69,70}$ miRNAs were first described in 1980, but it was not until recently that these molecules started to gain visibility in the context of pregnancy. Not only can the study of these molecules enhance our knowledge concerning the pathogenesis of prematurity, but they have also emerged as potential biomarkers and therapeutic tools against PTB and PPROM.

MicroRNAs are expressed in the placenta and can be detected in gestational tissues and maternal plasma. Three miRNA clusters are specifically related to placental development: the chromosome 14 miRNA cluster (C14MC), the C19MC, and the miR-371 cluster. The miRNAs have been recently reported to play a role in the regulation of normal labor as well as in prematurity. ${ }^{71,72}$ Molecules from the miRNA-200 family regulate the expression of zinc-finger E-box binding homeobox proteins ZEB1 and ZEB2. These 2 crucial proteins suppress the expression of the oxytocin receptor and connexin 43 prior to the onset of labor, thereby maintaining uterine quiescence, ${ }^{73}$ and have been demonstrated to block oxytocininduced contractility in human myometrial cells. ${ }^{74}$

A study by Elovitz et a ${ }^{75}$ associated increased expression of miR-145, miR-143, and miR-199 in cervical cells in American women with cervical remodeling that delivered preterm. The authors suggested that increased miR-145 leads to a decrease in the adhesion protein JAM-A, thus increasing the permeability of the epithelial barrier in the cervix and favoring PTL. In a study on 56 Mexican pregnant women, higher expression of 6 cervical miRNAs, that is, miR-21, 29b, 30e, 142, 148b, and 223 of 800 miRNAs profiled were significantly associated with a shorter length of gestation after adjustment for age, education, body mass index, parity, and smoke exposure; 5 of those (miR$21,29 \mathrm{~b}, 30 \mathrm{e}, 142$, and 148b) were differently expressed in preterm when compared to term pregnancies. ${ }^{76}$ The mRNA targets for these miRNAs are involved in innate and adaptive immune responses, especially with the TNF-induced inflammatory response and DNA methyltransferases that regulate DNA replication. This latter observation illustrates the interconnection between these 2 epigenetic mechanisms, that is, miRNAs and DNA methylation, and their involvement in the preterm termination of pregnancy. Despite the need for larger prospective studies, the reproducibility of findings reported by these 2 studies performed with distinct populations during second-trimester pregnancies indicate that these local miRNAs have great potential to be used as noninvasive cervical biomarkers for PTB in the near future, at least for PTB phenotypes associated with cervical changes.

Systemically, however, the results available in the literature so far do not seem as promising. A recent study found that miRNA profiles in serum were not different between women with PTL and women who delivered at term, although the sample population of this study was small, and the authors did not investigate miRNAs encapsulated by extracellular vesicles or attached to argonaute protein, forms that increase miRNA stability in the circulation. ${ }^{75}$

Altered levels of miR-338, miR-199a-3p, and miR-223 have been associated with PTL in other gestational tissues. miR-338 targets PLA2G4B mRNA, which is translated into phospholipase A2. The chorioamniotic membranes of PTL patients present decreased expression of this miRNA, leading to increased levels of phospholipase A2, which results in increased prostaglandin synthesis that in turn initiates the PTL cascade. ${ }^{72}$ Acting in this same pathway, decreased expression of miR-199a$3 p$ in mouse myometrium increases prostaglandin production by reducing the suppression of cyclooxygenase $2 .{ }^{77}$ In a recent study, miR-223 levels in the amnion were inversely associated with the risk of PTL and PPROM. ${ }^{78}$ Although functional analyses were not performed in this study, targets for miR-223 include a number of genes involved in the same pathways activated in PTL and PPROM, including inflammation, immune cell responses, and hematopoietic differentiation. ${ }^{79}$

As intracellular modulators of gene transcription, miRNAs also have an impact on the response to pathogens and therefore may be implicated in infection-associated adverse gestational outcomes, as demonstrated by Garg et al. ${ }^{80}$ Nuclear factor- $\mathrm{\kappa B}$ is a heterodimer composed of 2 subunits from p65 (RelA), RelB, c-Rel, p52, and/or p50. ${ }^{81}$ Upon activation, NF- $\mathrm{KB}$ enters the nucleus to regulate gene expression. Using culture methods, authors have identified an miRNA that regulates NF- $\mathrm{kB}$ p65 mRNA, the miR-329. This miRNA regulates TLR2-mediated apoptosis induced by the administration of peptidoglycan (PDG) from gram-positive bacteria in first-trimester TLR6 trophoblasts. PDG upregulates miR-329, which targets NF- $\mathrm{BB}$ p65 mRNA, thus decreasing expression of IL-6 and leading to apoptosis. miR-23a and let-7c have also been identified to play a part in IL-6 inhibition under these conditions. By inference, miR-329, miR-23a, and let-7c may be important factors in triggering placental injury and adverse pregnancy outcomes as modulators of TLR-mediated inflammation and apoptosis at the maternal-fetal interface.

Additionally, some miRNAs such as miR-16, 20a, 26b, 29b, $144,146 \mathrm{~b}-5 \mathrm{p}, 155,210$, and 335 have been found to present altered expression under experimental conditions of oxidative stress. ${ }^{82-84}$ Unopposed reactive oxygen species (or oxidative stress $[\mathrm{OS}]$ ) and the consequent oxidative damage are wellknown mechanisms involved in PTL and especially in 
PPROM. ${ }^{85,86}$ Although it is possible that these molecules could be implicated in OS-induced PTB, the role of these miRNAs in OS-induced pathways in the setting of prematurity is yet to be investigated.

Undoubtedly, miRNAs add more complexity to the finetuned regulation of birth onset, and there is still much to be explored concerning their mechanisms of action. Importantly, the discovery of new miRNAs involved in the regulation of birth timing increases the possibility of approaches to PTL prediction and to new therapeutic targets. More investigations regarding the biological effect of miRNAs will bring new insight into the epigenetic regulation of physiological and pathological termination of pregnancy.

\section{Conclusion}

In combination, genomic and epigenomic profiles may provide valuable insight into the mechanisms underlying pregnancies complicated by PTL and PPROM. More systematic and unbiased genetic and epigenetic approaches are needed in future studies to enhance our understanding of the genetic and epigenetic basis of human birth timing and hopefully provide knowledge that can be translated into clinical practice.

\section{Declaration of Conflicting Interests}

The author(s) declared no potential conflicts of interest with respect to the research, authorship, and/or publication of this article.

\section{Funding}

The author(s) received no financial support for the research, authorship, and/or publication of this article.

\section{References}

1. Giarratano G. Genetic influences on preterm birth. MCN Am J Matern Child Nurs. 2006;31(3):169-175.

2. Callaghan WM, MacDorman MF, Rasmussen SA, Qin C, Lackritz EM. The contribution of preterm birth to infant mortality rates in the United States. Pediatrics. 2006;118(4):1566-1573.

3. Behrman RE, Butler AS, eds. Preterm Birth: Causes, Consequences, and Prevention. Washington, DC: The National Academies Collection: Reports funded by National Institutes of Health; 2007.

4. Beck S, Wojdyla D, Say L, et al. The worldwide incidence of preterm birth: a systematic review of maternal mortality and morbidity. Bull World Health Organ. 2010;88(1):31-38.

5. Arpino C, D’Argenzio L, Ticconi C, et al. Brain damage in preterm infants: etiological pathways. Ann Ist Super Sanita. 2005; 41(2):229-237.

6. Romero R, Dey SK, Fisher SJ. Preterm labor: one syndrome, many causes. Science. 2014;345(6198):760-765.

7. Ramos B de A, Kanninen TT, Sisti G, Witkin SS. Microorganisms in the female genital tract during pregnancy: tolerance versus pathogenesis. Am J Reprod Immunol. 2015;73(5):383-389.

8. Patni S, Flynn P, Wynen LP, et al. An introduction to Toll-like receptors and their possible role in the initiation of labour. BJOG. 2007;114(11):1326-1334.
9. Christiaens I, Zaragoza DB, Guilbert L, Robertson SA, Mitchell $\mathrm{BF}$, Olson DM. Inflammatory processes in preterm and term parturition. J Reprod Immunol. 2008;79(1):50-57.

10. Romero R, Espinoza J, Kusanovic JP, et al. The preterm parturition syndrome. BJOG. 2006;113(suppl 3):17-42.

11. Goldenberg RL, Culhane JF, Iams JD, Romero R. Epidemiology and causes of preterm birth. Lancet. 2008;371(9606):75-84.

12. Ramos BR, Mendes ND, Tanikawa AA, et al. Ancestry informative markers and selected single nucleotide polymorphisms in immunoregulatory genes on preterm labor and preterm premature rupture of membranes: a case control study. BMC Pregnancy Childbirth. 2016;16:30.

13. Karody VR, Le M, Nelson S, et al. A TIR domain receptorassociated protein (TIRAP) variant SNP (rs8177374) confers protection against premature birth. J Perinatol. 2013;33(5):341-346.

14. Shah NR, Bracken MB. A systematic review and meta-analysis of prospective studies on the association between maternal cigarette smoking and preterm delivery. Am J Obstet Gynecol. 2000; 182(2):465-472.

15. Menon R, Boldogh I, Urrabaz-Garza R, et al. Senescence of primary amniotic cells via oxidative DNA damage. PLoS One. 2013;8(12): e83416.

16. Ferrero DM, Larson J, Jacobsson B, et al. Cross-Country Individual Participant Analysis of 4.1 Million Singleton Births in 5 Countries with Very High Human Development Index Confirms Known Associations but Provides No Biologic Explanation for 2/ 3 of All Preterm Births. PLoS One. 2016;11(9): e0162506.

17. Boyd HA, Poulsen G, Wohlfahrt J, et al. Maternal contributions to preterm delivery. Am J Epidemiol. 2009;170(11):1358-1364.

18. Bhattacharya S, Raja EA, Mirazo ER, et al. Inherited predisposition to spontaneous preterm delivery. Obstet Gynecol. 2010; 115(6):1125-1133.

19. Treloar SA, Macones GA, Mitchell LE, Martin NG. Genetic influences on premature parturition in an Australian twin sample. Twin Res. 2000;3(2):80-82.

20. Clausson B, Lichtenstein P, Cnattingius S. Genetic influence on birthweight and gestational length determined by studies in offspring of twins. BJOG. 2000;107(3):375-381.

21. Anum EA, Springel EH, Shriver MD, Strauss JF III. Genetic contributions to disparities in preterm birth. Pediatr Res. 2009; 65(1):1-9.

22. Vinikoor LC, Kaufman JS, MacLehose RF, Laraia BA. Effects of racial density and income incongruity on pregnancy outcomes in less segregated communities. Soc Sci Med. 2008;66(2):255-259.

23. Romero R, Espinoza J, Goncalves LF, Kusanovic JP, Friel L, Hassan S. The role of inflammation and infection in preterm birth. Semin Reprod Med. 2007;25(1):21-39.

24. Holst D, Garnier Y. Preterm birth and inflammation- The role of genetic polymorphisms. Eur J Obstet Gynecol Reprod Biol. 2008; 141(1):3-9.

25. Wilcox AJ, Skaerven R, Lie RT. Familial patterns of preterm delivery: Maternal and fetal contributions. Am J Epidemiol. 2008;167(4):474-479.

26. Svensson AC, Sandin S, Cnattingius S, et al. Maternal effects for preterm birth: A genetic epidemiologic study of 630,000 families. Am J Epidemiol. 2009;170(11):1365-1372. 
27. Wang H, Ogawa M, Wood JR, et al. Genetic and epigenetic mechanisms combine to control MMP1 expression and its association with preterm premature rupture of membranes. Hum Mol Genet. 2008;17(8):1087-1096.

28. Kim J, Pitlick MM, Christine PJ, et al. Genome-wide analysis of DNA methylation in human amnion. Scientific World Journal. 2013;2013:67815.

29. Yilmaz Y, Verdi H, Taneri A, et al. Maternal-fetal proinflammatory cytokine gene polymorphism and preterm birth. DNA Cell Biol. 2012;31(1):92-97.

30. Schmid M, Haslinger P, Stary S, Leipold H, Egarter C, Grimm C. Interleukin-1 beta gene polymorphisms and preterm birth. Eur $J$ Obstet Gynecol Reprod Biol. 2012;165(1):33-36.

31. Jones NM, Holzman C, Tian Y, et al. Innate immune system gene polymorphisms in maternal and child genotype and risk of preterm delivery. J Matern Fetal Neonatal Med. 2012;25(3): 240-247.

32. Jafarzadeh L, Danesh A, Sadeghi M, Heybati F, Hashemzadeh M. Analysis of Relationship between Tumor Necrosis Factor Alpha Gene (G308A Polymorphism) with Preterm Labor. Int J Prev Med. 2013;4(8):896-901.

33. Moura E, Mattar R, de Souza E, Torloni MR, Goncalves-Primo A, Daher S. Inflammatory cytokine gene polymorphisms and spontaneous preterm birth. J Reprod Immunol. 2009;80(1-2): 115-121.

34. Varner MW, Esplin MS. Current understanding of genetic factors in preterm birth. BJOG. 2005;112(suppl 1):28-31.

35. Liang M, Wang X, Li J, et al. Association of combined maternalfetal TNF-alpha gene G308A genotypes with preterm delivery: a gene-gene interaction study. J Biomed Biotechnol. 2010;2010: 396184.

36. El-Bastawissi AY, Williams MA, Riley DE, Hitti J, Krieger JN. Amniotic fluid interleukin-6 and preterm delivery: a review. Obstet Gynecol. 2000;95(6 pt 2):1056-1064.

37. Jacobsson B, Mattsby-Baltzer I, Andersch B, et al. Microbial invasion and cytokine response in amniotic fluid in a Swedish population of women with preterm prelabor rupture of membranes. Acta Obstet Gynecol Scand. 2003;82(5):423-431.

38. Kalinka J, Bitner A. Selected cytokine gene polymorphisms and the risk of preterm delivery in the population of Polish women. Ginekol Pol. 2009;80(2):111-117.

39. Velez DR, Fortunato SJ, Williams SM, Menon R. Interleukin-6 (IL-6) and receptor (IL6-R) gene haplotypes associate with amniotic fluid protein concentrations in preterm birth. Hum Mol Genet. 2008;17(11):1619-1630.

40. Speer EM, Gentile DA, Zeevi A, Pillage G, Huo D, Skoner DP. Role of single nucleotide polymorphisms of cytokine genes in spontaneous preterm delivery. Hum Immunol. 2006;67(11): 915-923

41. Abrahams VM, Aldo PB, Murphy SP, et al. TLR6 modulates first trimester trophoblast responses to peptidoglycan. J Immunol. 2008;180(9):6035-6043

42. Ozinsky A, Underhill DM, Fontenot JD, et al. The repertoire for pattern recognition of pathogens by the innate immune system is defined by cooperation between toll-like receptors. Proc Natl Acad Sci USA. 2000;97(25):13766-13771.
43. Koga K, Mor G. Toll-like receptors at the maternal-fetal interface in normal pregnancy and pregnancy disorders. Am J Reprod Immunol. 2010;63(6):587-600.

44. Sutherland AM, Walley KR, Russell JA. Polymorphisms in CD14, mannose-binding lectin, and toll-likereceptor-2 are associated with increased prevalence of infection in critically ill adults. Crit Care Med. 2005;33(3):638-644.

45. Bitner A, Sobala W, Kalinka J. Association between maternal and fetal TLR4 (896A $>$ G, 1196C $>$ T) gene polymorphisms and the risk of preterm birth in the Polish population. Am $J$ Reprod Immunol. 2013;69(3):272-280.

46. Arbour NC, Lorenz E, Schutte BC, et al. TLR4 mutations are associated with endotoxin hyporesponsiveness in humans. Nat Genet. 2000;25(2):187-191.

47. Manuck TA, Major HD, Varner MW, Chettier R, Nelson L, Esplin MS. Progesterone receptor genotype, family history, and spontaneous preterm birth. Obstet Gynecol. 2010;115(4): 765-770.

48. Mann PC, Cooper ME, Ryckman KK, et al. Polymorphisms in the fetal progesterone receptor and a calcium-activated potassium channel isoform are associated with preterm birth in an Argentinian population. J Perinatol. 2013;33(5):336-340.

49. Diaz-Cueto L, Dominguez-Lopez P, Cantillo-Cabarcas J, PerezFigueroa G, Arechavaleta-Velasco M, Arechavaleta-Velasco F. Progesterone receptor gene polymorphisms are not associated with preterm birth in a Hispanic population. Int $J$ Gynaecol Obstet. 2008;103(2):153-157.

50. Kuessel L, Grimm C, Knöfler M, et al. Common oxytocin receptor gene polymorphisms and the risk for preterm birth. Dis Markers. 2013;34(1):51-56.

51. Haataja R, Karjalainen MK, Luukkonen A, et al. Mapping a new spontaneous preterm birth susceptibility gene, IGF1 R, using linkage, haplotype sharing, and association analysis. PLoS Genet. 2011;7(2): e1001293.

52. Karjalainen MK, Huusko JM, Ulvila J, et al. A potential novel spontaneous preterm birth gene, AR, identified by linkage and association analysis of $\mathrm{X}$ chromosomal markers. PLoS One. 2012;7(12): e51378.

53. Sheikh IA, Ahmad E, Jamal MS, et al. Spontaneous preterm birth and single nucleotide gene polymorphisms: a recent update. $B M C$ Genomics. 2016;17(suppl 9):759.

54. Alleman BW, Myking S, Ryckman KK, et al. No observed association for mitochondrial SNPs with preterm delivery and related outcomes. Pediatr Res. 2012;72(5):539-544.

55. Ramos BR, D'Elia MP, Amador MA, et al. Neither self-reported ethnicity nor declared family origin are reliable indicators of genomic ancestry. Genetica. 2016;144(3):259-265.

56. Parets SE, Conneely KN, Kilaru V, Menon R, Smith AK. DNA methylation provides insight into intergenerational risk for preterm birth in African Americans. Epigenetics. 2015;10(9):784-792.

57. Parets SE, Conneely KN, Kilaru V, et al. Fetal DNA Methylation Associates with Early Spontaneous Preterm Birth and Gestational Age. PLoS One. 2013;8(6): e67489.

58. McKay JA, Wong YK, Relton CL, Ford D, Mathers JC. Maternal folate supply and sex influence gene-specific DNA methylation in the fetal gut. Mol Nutr Food Res. 2011;55(11):1717-1723. 
59. Maloney CA, Hay SM, Rees WD. Folate deficiency during pregnancy impacts on methyl metabolism without affecting global DNA methylation in the rat fetus. Br J Nutr. 2007;97(6):1090-1098.

60. Timmermans S, Jaddoe VW, Hofman A, Steegers-Theunissen RP, Steegers EA. Periconception folic acid supplementation, fetal growth and the risks of lowbirth weight and preterm birth: the Generation R Study. Br J Nutr. 2009;102(5):777-785.

61. Chiaffarino F, Ascone GB, Bortolus R, et al. Effects of folic acid supplementation on pregnancy outcomes: a review of randomized clinical trials [in Italian]. Minerva Ginecol. 2010;62(4):293-301.

62. Porter TR, Kent ST, Su W, Beck HM, Gohlke JM. Spatio temporal association between birth outcomes and coke production and steel making facilities in Alabama, USA: a cross-sectional study. Environ Health. 2014;13:85.

63. Ferguson KK, McElrath TF, Chen YH, Mukherjee B, Meeker JD. Urinary phthalate metabolites and biomarkers of oxidative stress in pregnant women: a repeated measures analysis. Environ Health Perspect. 2015;123(3):210-216.

64. Li L, Zhang T, Qin XS, et al. Exposure to diethylhexyl phthalate (DEHP) results in a heritable modification of imprint genes DNA methylation in mouse oocytes. Mol Biol Rep. 2014; 41(3): 1227-1235.

65. Burris HH, Baccarelli AA, Wright RO, Wright RJ. Epigenetics: linking social and environmental exposures to preterm birth. Pediatr Res. 2016;79(1-2):136-140.

66. Sundrani DP, ChavanGautam PM, Mehendale SS, Joshi SR. Altered metabolism of maternal micronutrients and omega 3 fatty acids epigenetically regulate matrix metalloproteinases in preterm pregnancy: a novel hypothesis. Med Hypotheses. 2011; 77(5):878-883.

67. Bartel DP. MicroRNAs: genomics, biogenesis, mechanism, and function. Cell. 2004;116(2):281-297.

68. Da Sacco L, Masotti A. Recent insights and novel bioinformatics tools to understand the role of microRNAs binding to $5^{\prime}$ untranslated region. Int J Mol Sci. 2012;14(1):480-495.

69. Baek D, Villen J, Shin C, Camargo FD, Gygi SP, Bartel DP. The impact of microRNAs on protein output. Nature. 2008;455(7209): 64-71.

70. Flynt AS, Lai EC. Biological principles of microRNA-mediated regulation: shared themes amid diversity. Nat Rev Genet. 2008; 9(11):831-842.

71. Mayor-Lynn K, Toloubeydokhti T, Cruz AC, Chegini N. Expression profile of microRNAs and mRNAs in human placentas from pregnancies complicated by preeclampsia and preterm labor. Reprod Sci. 2011;18(1):46-56.

72. Montenegro D, Romero R, Kim SS, et al. Expression patterns of microRNAs in the chorioamniotic membranes: a role for
microRNAs in human pregnancy and parturition. J Pathol. 2009;217(1):113-121.

73. Renthal NE, Chen CC, Williams KC, et al. miR-200 family and targets, ZEB1 and ZEB2, modulate uterine quiescence and contractility during pregnancy and labor. Proc Natl Acad Sci USA. 2010;107(48):20828-20833.

74. Smith R, Paul J, Maiti K, Tolosa J, Madsen G. Recent advances in understanding the endocrinology of human birth. Trends Endocrinol Metab. 2012;23(10):516-523.

75. Elovitz MA, Anton L, Bastek J, Brown AG. Can microRNA profiling in maternal blood identify women at risk for preterm birth? Am J Obstet Gynecol. 2015;212(6):782.e1-e5.

76. Sanders AP, Gennings C, Svensson K, et al. Bacterial and cytokine mixtures predict the length of gestation and are associated with miRNA expression in the cervix. Epigenomics. 2017;9(1): 33-45.

77. Williams KC, Renthal NE, Condon JC, Gerard RD, Mendelson CR. MicroRNA-200a serves a key role in the decline of progesterone receptor function leading to term and preterm labor. Proc Natl Acad Sci USA. 2012;109(19):7529-7534.

78. Enquobahrie DA, Hensley M, Qiu C, et al. Candidate gene and microRNA expression in fetal membranes and preterm delivery risk. Reprod Sci. 2016;23(6):731-737.

79. Haneklaus M, Gerlic M, O’Neill LA, Masters SL. miR-223: infection, inflammation and cancer. J Intern Med. 2013;274(3): 215-226.

80. Garg M, Potter JA, Abrahams VM. Identification of microRNAs that regulate TLR2-mediated trophoblast apoptosis and inhibition of IL-6 mRNA. PLoS One. 2013;8(10): e77249.

81. Ghosh S, May MJ, Kopp EB. NF-kappa B and Rel proteins: evolutionarily conserved mediators of immune responses. Annu Rev Immunol. 1998;16:225-260.

82. Rudov A, Balduini W, Carloni S, Perrone S, Buonocore G, Albertini MC. Involvement of miRNAs in placental alterations mediated by oxidative stress. Oxid Med Cell Longev. 2014; 2014:103068.

83. Pineles BL, Romero R, Montenegro D, et al. Distinct subsets of microRNAs are expressed differentially in the human placentas of patients with preeclampsia. Am J Obstet Gynecol. 2007;196(3): 261.e1-e6.

84. Devlin C, Greco S, Martelli F, Ivan M. MiR-210: more than a silent player in hypoxia. IUBMB Life. 2011;63(2):94-100.

85. Menon R. Oxidative stress damage as a detrimental factor in preterm birth pathology. Front Immunol. 2014;5:567.

86. de Andrade Ramos BR, Witkin SS. The influence of oxidative stress and autophagy cross regulation on pregnancy outcome. Cell Stress Chaperones. 2016;21(5):755-762. 